\title{
Sire Evaluation Based on First Lactation Production Efficiency Traits in Murrah Buffaloes
}

\author{
D. Chakraborty, ${ }^{1, *}$ and S.S. Dhaka ${ }^{2}$
}

\begin{abstract}
${ }^{1}$ Animal Genetics and Breeding, Faculty of Veterinary Sciences \& Animal Husbandry, Sher-e-Kashmir University of Agricultural Sciences and Technology of Jammu (SKUAST-Jammu), R.S.Pura, Jammu- 181102, India

${ }^{2}$ Animal Genetics and Breeding, College of Animal Sciences, Lala Lajpat Rai University of Veterinary and Animal Sciences (LUVAS), Hisar- 125 004, Haryana, India
\end{abstract}

\begin{abstract}
The present investigation was undertaken on data of Murrah buffaloes from Buffalo Research Centre (BRC), Chaudhary Charan Singh Haryana Agricultural University, Hisar distributed over 20 years (1987 to 2006). The sire effects and ranks of 38 sires were estimated on the basis of their daughters' performance. The progeny group size of the sires ranged from 3 to 17. The sires were evaluated for the different first lactation production efficiency traits, viz. first lactation milk yield (FLMY), first lactation peak yield (FPY), persistency of first lactation milk yield (P), average yield per day of lactation (MY/FLL), milk yield per day of first calving interval $(\mathrm{MCl})$ and milk yield per day of age at second calving (MSC). Sire's breeding values were estimated by the best linear unbiased procedure (BLUP). The estimated breeding values (EBV) for FLMY, FPY, P, MY/FLL, MCl and MSC ranged from -288.42 to $362.20 \mathrm{~kg} ;-1.44$ to $4.36 \mathrm{~kg} ;-14.72$ to $21.09 ;-0.44$ to $0.63 \mathrm{~kg} / \mathrm{day} ;-0.40$ to $0.52 \mathrm{~kg}$ and -0.09 to $0.16 \mathrm{~kg}$, respectively. FLMY had high and significant productmoment and rank correlations with all other traits. The highest product-moment and rank correlations were obtained between FLMY and MSC to the tune of $0.863 \pm 0.043$ and $0.835 \pm 0.050$, respectively. The results indicated that sire coding 33 was the best and can be used for future breeding purpose.
\end{abstract}

Keywords: Estimated breeding values, persistency, first lactation milk yield, first lactation peak yield, Murrah buffaloes.

\section{INTRODUCTION}

Buffalo is the prime dairy animal of India and accounts about $36.24 \%$ of the total bovine population and $21.23 \%$ of the total livestock population [1]. The Murrah breed is one of the renowned breed of buffaloes in India by virtue of its milking capacity combined with tremendous potential for further genetic improvement. The main objective of the improvement programme through breeding is to select an individual with the highest breeding values to serve as parents of the next generation. The genetic gain associated with the production performance mainly comes through sires because of its higher selection intensity. Sire is known as half of the herd. Therefore, for any successful breeding strategy identification of genetically superior sires and their maximum utilization is the main criterion.

Best Linear Unbiased Prediction (BLUP) is the best method of sire evaluation. Selection of sires based on first lactation traits increase the genetic gain as it reduces the generation interval. Selection of superior sires based on production traits is mainly practised.

*Address correspondence to this author at the Animal Genetics and Breeding, Faculty of Veterinary Sciences \& Animal Husbandry, Sher-e-Kashmir University of Agricultural Sciences and Technology of Jammu (SKUASTJammu), R.S. Pura, Jammu- 181102, India;

E-mail: v.dr.dibyendu@gmail.com
But, production and reproduction traits are antagonistic to each other. Therefore, production efficiency traits like milk yield per day of lactation length (MY/FLL), milk yield per day of calving interval $(\mathrm{MCl})$ and milk yield per day of age at second calving (MSC) as combinations of production and reproduction can be used as selection tool [2]. The productive efficiency performance of dairy animal is determined by milk yields and duration of lactation. For this, the present investigation was carried out for finding the superior sires for future use based on the first lactation production efficiency traits.

\section{MATERIAL AND METHODS}

The present study was conducted on data of Murrah buffaloes maintained at Buffalo Research Centre (BRC), Chaudhary Charan Singh Haryana Agricultural University, Hisar, Haryana (India) for 20 years from 1987 to 2006. The sire effects and ranks of 38 sires were estimated based on their daughters' performance. Sires with less than three progenies were excluded from the present study. The progeny group size ranged from 3 to 17 . The sires were evaluated for the production efficiency traits, i.e., first lactation milk yield (FLMY), first lactation peak yield (FPY), persistency of first lactation milk yield $(P)=$ first lactation milk yield (FLMY) / first lactation peak yield (FPY), average yield per day of lactation $(\mathrm{MY} / \mathrm{FLL})=$ first lactation milk yield (FLMY) / first lactation length (FLL), lactation milk yield 
per day of first calving interval $(\mathrm{MCl})=$ first lactation milk yield (FLMY) / first calving interval $(\mathrm{FCl})$ and lactation milk yield per day of age at second calving $(\mathrm{MSC})=$ first lactation milk yield $(\mathrm{FLMY}) /$ age at second calving $[A S C=$ age at first caving $(A F C)+$ first calving interval $(\mathrm{FCl})]$.

Best Linear Unbiased Prediction (BLUP) was used for the estimation of breeding value of sires for different first lactation traits viz. FLMY, FPY, P, MY/FLL, MCI and MSC [3].

In matrix notation, the model of BLUP was as follows:

$$
Y=X b+Z u+e
$$

Where, $Y=$ vector of observations on the progeny of sire in $\mathrm{u}, \mathrm{X}=$ known design matrices that relate records $(Y)$ to fixed effects, $b=$ vector of fixed effect, $Z$ $=$ known design matrices that relate records $(\mathrm{Y})$ to random sires, $u=$ vector of random sire effects and $e=$ vector of residual effects.

$$
\begin{gathered}
\operatorname{Var}(u)=I \sigma_{s}^{2} \\
\operatorname{Var}(e)=I \sigma_{e}^{2} \\
\operatorname{Var}(Y)=Z^{\prime} Z+R
\end{gathered}
$$

The solution to $b$ and $u$ were obtained from mixed model equations given below:

$$
\left(\begin{array}{cc}
X^{\prime} X & X^{\prime} Z \\
Z^{\prime} X & Z^{\prime} Z+k
\end{array}\right)\left(\begin{array}{l}
b \\
u
\end{array}\right)=\left(\begin{array}{c}
X^{\prime} Y \\
Z^{\prime} Y
\end{array}\right)
$$

Where $\mathrm{k}=$ ratio of residual to sire variance components.

The ratio of residual and sire variance (k) components required for BLUP was obtained from the estimate of heritability from the same data as given below.

$$
k=\left(4-h^{2}\right) / h^{2}
$$

Where $\mathrm{h}^{2}=$ heritability of the trait.

\section{Product Moment Correlation}

Product moment correlation between the two traits was calculated as follows:

$$
r_{X y}=\sigma_{X Y} / \sqrt{ }\left(\sigma_{X}^{2} \sigma_{Y}^{2}\right)
$$

Where, $\quad r_{x y}=$ correlation coefficient (productmoment) between $X$ and $Y$ traits, $\sigma_{X Y}=$ covariance between $X$ and $Y$ traits, $\sigma^{2} X=$ variance of $X$ traits and $\sigma^{2} Y=$ variance of $Y$ traits.

\section{Spearman's Rank Correlation}

Sires were ranked based on their estimated breeding values for various traits. Spearman's rank correlations between ranks of estimated breeding values for various traits were calculated by the formula given below:

$$
r_{s}=1-\left[6 \Sigma d^{2} / N\left(N^{2}-1\right)\right]
$$

Where, $r_{\mathrm{s}}=$ rank correlation between ranks of sires breeding values for two traits, $\Sigma d^{2}=$ summation of the square difference between ranks of the same sire for different traits and $\mathrm{N}=$ number of sires.

The standard errors and significance of productmoment and rank correlations were computed using the formula [4].

\section{RESULTS AND DISCUSSION}

The breeding value along with ranks of the sires for FLMY, FPY, P, MY/FLL, MCI and MSC estimated by Best Linear Unbiased Prediction (BLUP) procedure of Henderson (1973) are presented in Table 1. The estimated breeding values (EBV) for FLMY, FPY, P, $\mathrm{AYL}, \mathrm{MCl}$ and $\mathrm{MSC}$ ranged from -288.42 to $362.20 \mathrm{~kg}$; -1.44 to $4.36 \mathrm{~kg} ;-14.72$ to $21.09 ;-0.44$ to $0.63 \mathrm{~kg} / \mathrm{day}$; -0.40 to $0.52 \mathrm{~kg}$ and -0.09 to $0.16 \mathrm{~kg}$, respectively. In the present study, the EBVs of sires for different first lactation production efficiency traits showed large variations which indicate large variations among sires' merit.

Estimated breeding values ranged -133.90 to $694.70 \mathrm{~kg}$ for MY in Murrah buffaloes, which was higher than the present study [5]. The range of MSC in Sahiwal cattle by BLUP method was reported as -0.057 to 0.147 [6]. The estimated breeding value of Persistency averaged as $-317.30 \pm 12.71$ in Murrah buffaloes [7]. Lower ranges for FLMY (553.86) and higher ranges for MY/FLL (1.87) and MY/FCl (2.14) in Holstein Friesian crossbred cattle were reported [8]. The higher range of estimated breeding values of sires by BLUP method for MYLL, MYFCI and MYASC as 5.4 to $7.44,3.13$ to 5.49 and 0.86 to 1.31 in Murrah buffaloes compared to the present study [9]. 
Table 1: Estimated Breeding Value of Sires Along with their Ranks for Different First Lactation Production Efficiency Traits in Murrah Buffaloes

\begin{tabular}{|c|c|c|c|c|c|c|c|c|c|c|c|c|c|c|}
\hline \multirow{2}{*}{$\begin{array}{l}\text { Sr. } \\
\text { No. }\end{array}$} & \multirow{2}{*}{$\begin{array}{l}\text { Sire } \\
\text { Code }\end{array}$} & \multirow{2}{*}{$\begin{array}{l}\text { No. } \\
\text { of } \\
\text { obs. }\end{array}$} & \multicolumn{2}{|c|}{ FLMY } & \multicolumn{2}{|c|}{ FPY } & \multicolumn{2}{|c|}{$\mathbf{P}$} & \multicolumn{2}{|c|}{ MY/FLL } & \multicolumn{2}{|c|}{ MCI } & \multicolumn{2}{|c|}{ MSC } \\
\hline & & & EBV & Rank & EBV & Rank & EBV & Rank & EBV & Rank & EBV & Rank & EBV & Rank \\
\hline 1 & 3 & 3 & -105.29 & 30 & -0.33 & 28 & -1.53 & 24 & -0.10 & 26 & -0.25 & 33 & -0.03 & 28 \\
\hline 2 & 4 & 7 & 14.48 & 20 & -0.17 & 23 & 7.36 & 9 & -0.06 & 22 & 0.08 & 13 & 0.001 & 20 \\
\hline 3 & 6 & 11 & 112.75 & 7 & 0.75 & 4 & -5.73 & 30 & 0.63 & 1 & 0.44 & 2 & 0.08 & 4 \\
\hline 4 & 7 & 3 & -54.88 & 26 & 0.09 & 14 & -7.28 & 31 & -0.18 & 32 & -0.30 & 37 & 0.06 & 6 \\
\hline 5 & 9 & 5 & -72.97 & 27 & -0.6 & 33 & -1.47 & 22 & -0.22 & 35 & 0.04 & 15 & 0.01 & 15 \\
\hline 6 & 11 & 4 & -114.56 & 31 & 0.25 & 8 & -13.98 & 37 & -0.12 & 28 & -0.13 & 27 & -0.02 & 27 \\
\hline 7 & 12 & 6 & -30.65 & 25 & -0.18 & 24 & 1.57 & 16 & -0.10 & 25 & -0.04 & 21 & -0.01 & 22 \\
\hline 8 & 13 & 7 & -24.43 & 24 & -0.54 & 31 & -1.48 & 23 & 0.31 & 6 & -0.27 & 34 & -0.08 & 37 \\
\hline 9 & 15 & 5 & 112.07 & 8 & -0.35 & 30 & 21.09 & 1 & -0.08 & 23 & 0.02 & 16 & 0.04 & 12 \\
\hline 10 & 16 & 15 & -21.96 & 23 & 0.15 & 11 & -3.17 & 26 & -0.13 & 29 & 0.18 & 10 & 0.02 & 14 \\
\hline 11 & 17 & 4 & 79.52 & 11 & 0.67 & 5 & -4.03 & 27 & 0.12 & 11 & 0.24 & 7 & 0.04 & 10 \\
\hline 12 & 18 & 9 & 64.37 & 13 & -0.18 & 25 & 12.37 & 6 & -0.08 & 24 & -0.30 & 36 & 0.004 & 18 \\
\hline 13 & 19 & 9 & 19.96 & 18 & 0.15 & 12 & 0.11 & 18 & 0.09 & 12 & 0.18 & 9 & 0.003 & 19 \\
\hline 14 & 20 & 5 & -125.31 & 33 & -0.56 & 32 & -5.03 & 29 & -0.31 & 37 & -0.11 & 25 & -0.02 & 26 \\
\hline 15 & 21 & 5 & 58.05 & 14 & 0.03 & 18 & 1.86 & 14 & 0.07 & 15 & -0.04 & 20 & 0.005 & 17 \\
\hline 16 & 22 & 10 & -116.49 & 32 & 0.06 & 17 & -12.33 & 34 & -0.10 & 27 & -0.02 & 18 & -0.05 & 30 \\
\hline 17 & 23 & 3 & 99.43 & 10 & 0.51 & 7 & 3.02 & 13 & 0.33 & 5 & 0.28 & 5 & 0.05 & 7 \\
\hline 18 & 29 & 8 & -288.42 & 38 & -1.44 & 38 & -14.72 & 38 & -0.44 & 38 & -0.40 & 38 & -0.09 & 38 \\
\hline 19 & 31 & 17 & 160.14 & 5 & -1.35 & 36 & 18.07 & 2 & 0.08 & 13 & 0.01 & 17 & 0.01 & 16 \\
\hline 20 & 32 & 5 & -85.20 & 29 & -0.76 & 34 & -2.40 & 25 & -0.14 & 30 & -0.07 & 24 & -0.07 & 33 \\
\hline 21 & 33 & 10 & 362.2 & 1 & 4.36 & 1 & 17.92 & 3 & 0.45 & 3 & 0.52 & 1 & 0.16 & 1 \\
\hline 22 & 35 & 3 & 37.67 & 16 & 0.18 & 10 & -4.54 & 28 & 0.20 & 8 & -0.05 & 22 & -0.02 & 25 \\
\hline 23 & 36 & 4 & -78.79 & 28 & 0.24 & 9 & 0.31 & 17 & -0.04 & 21 & -0.21 & 30 & -0.07 & 34 \\
\hline 24 & 37 & 4 & 294.23 & 2 & 1.59 & 2 & 7.35 & 10 & 0.16 & 9 & 0.42 & 3 & 0.10 & 2 \\
\hline 25 & 49 & 4 & 175.44 & 3 & 1.39 & 3 & 5.18 & 11 & 0.54 & 2 & 0.33 & 4 & 0.07 & 5 \\
\hline 26 & 51 & 11 & 15.93 & 19 & -1.37 & 37 & 16.47 & 4 & -0.26 & 36 & -0.24 & 32 & -0.04 & 29 \\
\hline 27 & 54 & 3 & -13.89 & 22 & -0.14 & 21 & -1.12 & 21 & 0.04 & 18 & -0.15 & 28 & -0.01 & 23 \\
\hline 28 & 57 & 3 & 167.32 & 4 & -0.26 & 27 & 14.21 & 5 & -0.21 & 34 & -0.19 & 29 & 0.04 & 13 \\
\hline 29 & 59 & 9 & -140.00 & 35 & -0.76 & 35 & -7.47 & 32 & -0.20 & 33 & 0.04 & 14 & -0.08 & 35 \\
\hline 30 & 60 & 4 & -126.15 & 34 & -0.05 & 20 & -12.57 & 35 & 0.06 & 16 & -0.12 & 26 & -0.06 & 31 \\
\hline 31 & 62 & 5 & 8.68 & 21 & -0.19 & 26 & 1.74 & 15 & 0.05 & 17 & -0.28 & 35 & -0.003 & 21 \\
\hline 32 & 65 & 4 & 105.02 & 9 & 0.01 & 19 & 9.56 & 8 & -0.002 & 20 & 0.12 & 12 & 0.05 & 9 \\
\hline 33 & 66 & 4 & 57.36 & 15 & 0.09 & 15 & 4.77 & 12 & 0.13 & 10 & 0.15 & 11 & 0.04 & 11 \\
\hline 34 & 67 & 4 & -160.58 & 37 & -0.14 & 22 & -13.50 & 36 & 0.27 & 7 & -0.03 & 19 & -0.07 & 32 \\
\hline 35 & 69 & 5 & 20.04 & 17 & 0.15 & 13 & -0.63 & 19 & 0.08 & 14 & -0.24 & 31 & -0.01 & 24 \\
\hline 36 & 70 & 4 & 73.68 & 12 & 0.54 & 6 & -0.68 & 20 & 0.40 & 4 & 0.22 & 8 & 0.05 & 8 \\
\hline 37 & 73 & 3 & 151.27 & 6 & 0.09 & 16 & 12.19 & 7 & 0.01 & 19 & 0.25 & 6 & 0.09 & 3 \\
\hline 38 & 74 & 5 & -140.62 & 36 & -0.34 & 29 & -8.49 & 33 & -0.17 & 31 & -0.06 & 23 & -0.08 & 36 \\
\hline
\end{tabular}

EBV= Estimated Breeding Value, FLMY= First lactation milk yield, FPY= First lactation peak yield, $\mathrm{P}=\mathrm{Persistency}$ of first lactation milk yield, $\mathrm{MY} / \mathrm{FLL}=\mathrm{Average}$ yield per day of the first lactation, $\mathrm{MCl}=$ Lactation milk yield per day of first calving interval, $\mathrm{MSC}=$ Lactation milk yield per day of age at second calving.

\section{Product Moment Correlations}

The product-moment correlations among sires' estimated breeding values for the first lactation production efficiency traits (FLMY, FPY, P, MY/FLL, $\mathrm{MCl}$ and $\mathrm{MSC}$ ) are presented in Table 2. The productmoment correlations among various traits were high and significant except $\mathrm{P}$ with FPY, MY/FLL and $\mathrm{MCl}$ where low but positive correlations were obtained. The highest product-moment correlation was obtained between FLMY and MSC and was $0.863 \pm 0.043$ (Table 2). On the other hand, the lowest product-moment correlation was obtained between FPY and P (Table 2). FLMY and MSC had highly significant product-moment correlations with other traits. High product-moment correlations among 305 days $\mathrm{MY}$ and $\mathrm{P}$ in Murrah buffaloes were reported [7]. 
Table 2: Product-Moment Correlation (Above Diagonal) and Rank Correlation (below Diagonal) for Various Traits

\begin{tabular}{|c|c|c|c|c|c|c|}
\hline & FLMY & FPY & P & MY/FLL & MCI & MSC \\
\hline \hline FLMY & - & $0.643^{* *} \pm 0.098$ & $0.768^{* *} \pm 0.068$ & $0.574^{* *} \pm 0.112$ & $0.651^{* *} \pm 0.096$ & $0.863^{* *} \pm 0.043$ \\
\hline FPY & $0.468^{* *} \pm 0.130$ & - & $0.187 \pm 0.161$ & $0.632^{\star *} \pm 0.100$ & $0.675^{* *} \pm 0.091$ & $0.703^{* *} \pm 0.084$ \\
\hline P & $0.778^{* *} \pm 0.066$ & $0.026 \pm 0.167$ & - & $0.122 \pm 0.164$ & $0.250 \pm 0.156$ & $0.556^{* *} \pm 0.115$ \\
\hline MY/FLL & $0.555^{* *} \pm 0.115$ & $0.662^{* *} \pm 0.094$ & $0.210 \pm 0.159$ & - & $0.633^{* *} \pm 0.100$ & $0.493^{* *} \pm 0.126$ \\
\hline MCI & $0.548^{* *} \pm 0.117$ & $0.565^{* *} \pm 0.113$ & $0.246 \pm 0.157$ & $0.537^{* *} \pm 0.119$ & - & $0.708^{* *} \pm 0.083$ \\
\hline MSC & $0.835^{* *} \pm 0.050$ & $0.597^{* *} \pm 0.107$ & $0.539^{* *} \pm 0.118$ & $0.445^{* *} \pm 0.134$ & $0.657^{* *} \pm 0.095$ & - \\
\hline
\end{tabular}

Figures above diagonal are estimates of product-moment correlations.

Figures below diagonal are estimates of rank correlations.

${ }^{* *} \mathrm{P}<0.01$

Table 3: Ranking of Top Five Sires for Different First Lactation Production Efficiency Traits in Murrah Buffaloes

\begin{tabular}{|c|c|c|c|c|c|c|}
\hline Rank & FLMY & FPY & P & MY/FLL & MCI & MSC \\
\hline \hline $\mathbf{1}$ & $362.20(33)$ & $4.36(33)$ & $21.09(15)$ & $0.63(06)$ & $0.52(33)$ & $0.16(33)$ \\
\hline $\mathbf{2}$ & $294.23(37)$ & $1.59(37)$ & $18.07(31)$ & $0.54(49)$ & $0.44(06)$ & $0.10(37)$ \\
\hline $\mathbf{3}$ & $175.44(49)$ & $1.39(49)$ & $17.92(33)$ & $0.45(33)$ & $0.42(37)$ & $0.09(73)$ \\
\hline $\mathbf{4}$ & $167.32(57)$ & $0.75(06)$ & $16.47(51)$ & $0.40(69)$ & $0.33(49)$ & $0.08(06)$ \\
\hline $\mathbf{5}$ & $160.14(31)$ & $0.67(17)$ & $14.21(57)$ & $0.33(23)$ & $0.28(23)$ & $0.07(49)$ \\
\hline
\end{tabular}

Figures in parenthesis are codes of sires.

\section{Rank Correlations}

Sires were ranked based on their breeding values estimated by BLUP procedure. The value of rank correlations among these traits ranged from 0.026 to 0.835 . The highest rank correlation was obtained between FLMY and MSC, whereas the lowest rank correlation was obtained between FPY and P (Table 2). The rank correlations for all the traits under present study were positive. FLMY and MSC had highly significant rank correlations with other traits that indicate that the sire that was good for FLMY and MSC was also good for other traits. Bull's estimated breeding value for peak yield had the highest rank $(0.74)$ and product-moment correlation $(0.71)$ with lactation yield in Frieswal cattle [10].

\section{Ranking of Sires}

The sire evaluation is generally aimed to select the first few top-ranking sires based on their net merit. There were changes in the rank of first few top sires by BLUP method of sire's evaluation for different traits under study. These results indicated that all sires would not rank the same for first lactation production efficiency traits. The results presented in Table 3 showed that sire coding 33 was on top five for every trait under study and was on the first position for FLMY,
FPY, $\mathrm{MCl}$ \& MSC and on the third position for $\mathrm{P}$ \& MY/FLL. As the sire coded 33 was superior for production as well as production efficiency traits which include both production and reproduction traits, so, 33 coded sire is the best and can be used for future breeding purpose.

\section{CONCLUSION}

The EBVs of sires showed significant variation between sires for all first lactation production efficiency traits. There were changes in the rank of first few top sires by BLUP method of sire evaluation. Selection of sires based on first lactation milk yield would be a better choice as it had high product moments as well as rank correlations with all the traits included in the study. The high and significant product-moment and rank correlations suggest that MSC can also be taken as a criterion for selecting Murrah bulls for the future breeding programme. The results of the present study indicated that sire coding 33 was the best and can be used for future breeding purpose.

\section{REFERENCES}

[1] Anonymous. $19^{\text {th }}$ Livestock Census. Department of Animal Husbandry, Dairying and Fisheries, Govt. of India, New Delhi. 2012. 
[2] Chakraborty, D, Dhaka SS, Pander BL, Yadav AS. Genetic studies on production efficiency traits in Murrah buffaloes. Indian J Anim Sci 2010; 80(9): 898-901.

[3] Henderson CR. Sire evaluation and genetic trends. Proceedings of the animal breeding and genetics symposium in Honor of Dr. Jay L. Lush, ASAS and ADSA, Champaign, Illinois 1973; pp. 10-41.

https://doi.org/10.1093/ansci/1973.Symposium.10

[4] Snedecor GW, Cochran WG. Statistical methods. $8^{\text {th }}$ Ed. lowa State University Press, Ames, USA 1994.

[5] Kuralkar SV. Relationship among early performance, lifetime production and reproduction traits in Murrah buffaloes. Ph.D. thesis, Indian Veterinary Research Institute (Deemed University), Izatnagar, India 1996.

[6] Dhaka SS, Chaudhary SR, Raheja KL, Yadav AS, Pander BL. Accuracy of different methods of sire evaluation for production efficiency trait in Sahiwal cattle. Indian J Anim Sci 2004; 74(3): 296-8.
[7]

Geetha E, Chakravarty AK. Random regression test day model for estimation of breeding values for persistency of first lactation milk yield in Murrah buffaloes. Indian J Dairy Sci 2006; 59: 95-9.

[8] Dash SK, Gupta AK, Singh A, Chakravarty AK, Madhusoodanan M, Valsalan J, Shivahre PR, Hussain A. Evaluation of efficiency of sire model and animal model in Holstein Friesian crossbred cattle considering first lactation production and fertility traits. Veterinary World 2014; 7: 9337. https://doi.org/10.14202/vetworld.2014.933-937

[9] Kamaldeep, Yadav AS, Dhaka SS, Magotra A, Malik A Jakhar V. Efficiency of sire evaluation methods to improve milk yield of Murrah buffaloes. Haryana Vet 2016; 55(1): 1-5.

[10] Gaur GK. Estimated breeding values of Frieswal bulls for the performance traits. Indian J Anim Sci 2003; 73: 79-82.

\section{DOI: https://doi.org/10.6000/1927-520X.2020.09.09}

(C) 2020 Chakraborty and Dhaka; Licensee Lifescience Global.

This is an open access article licensed under the terms of the Creative Commons Attribution Non-Commercial License (http://creativecommons.org/licenses/by-nc/3.0/) which permits unrestricted, non-commercial use, distribution and reproduction in any medium, provided the work is properly cited. 